\title{
A REVIEW OF ANALYTICAL METHODS FOR DETERMINATION OF TYPE- II ANTIDIABETIC DRUGS IN PHARMACEUTICALS AND BIOLOGICAL MATRICES
}

\author{
BADIKELA RAMAKRISHNA ${ }^{1 *}$, SUMANTA MONDAL ${ }^{2}$
}

${ }^{1}$ Department of Pharmaceutical Analysis and QA, Guru Nanak Institutions Technical Campus, School of Pharmacy, Ibrahimpatnam, Ranga Reddy, Telangana, India. ${ }^{2}$ Department of Pharmaceutical Chemistry, GITAM Institute of Pharmacy, GITAM Deemed to be University, Gandhi Nagar, Rushikonda, Visakhapatnam, Andhra Pradesh, India. Email: logonanalysis@gmail.com

Received: 19 October 2020, Revised and Accepted: 23 November 2020

\section{ABSTRACT}

Its a meglitinide analog is an oral symptom designed to common hour aldohexose excursions. Through not an antidiabetic, it acts in AN analogous manner by binding to antidiabetic receptor likewise on alternative one distinct receptor-» closure of adenosine triphosphate dependent $\mathrm{K}+$ channel-» of depolarization-» internal secretion unharnesses. Repaglinide induces fast onset short-lasting internal secretion discharged. It is administered antero every main meal to stabilize postprandial hyperglycemia; the dose ought to be emitted if a food material is incomprehensible. Because of less permanent action, it perhaps had a lower risk of the seriousness of hypoglycemia. Repaglinide is indicated solely in type-II DM as another to sulfonylureas, or to supplement metformin/long internal secretion. It ought to be avoided in disease. This review delivers a detail description totally different of various analytical ways were printed for the estimation of repaglinide and its combination medicine in prescription drugs and biological matrices. This assessment encompasses different analytical ways such as chemical analysis ways, aggressive liquid activity (HPLC), superior thin-layer activity (HPTLC), liquid chromatography-mass spectroscopic analysis (LC-MS), and ultra-performance liquid activity (UPLC), GC-MS, [LC-ESI-MS-MS], capillary activity (CE), titrimetric and chemical science technique, and designation study for the estimation of repaglinide and together with a mixture.

Keywords: Biological matrices, Chromatography, Repaglinide, Analytical methods, Type-II diabetic drugs, ICH guidelines.

(C) 2021 The Authors. Published by Innovare Academic Sciences Pvt Ltd. This is an open access article under the CC BY license (http://creativecommons.org/ licenses/by/4.0/) DOI: http://dx.doi.org/10.22159/ajpcr.2021v14i1.40049. Journal homepage: https://innovareacademics.in/journals/index.php/ajpcr

\section{INTRODUCTION}

Repaglinide is a new carboxymethyl benzoic acid derivative, also known as 2-ethoxy -4-[2-[[3-methyl-1-[2-(1-piperidinyl) phenyl] butyl] amino]-2-oxoethyl] (Fig. 1). It is a novel prandial glucose regulator for the treatment of type-II diabetes mellitus [1]. It reduces fasting glucose concentrations in patients with type-II diabetes mellitus. It helps to control the blood sugar levels by pancreas increases insulin levels. Repaglinide is an oral anti hyperglycemia agent used for the treatment of non-insulin-dependent diabetes mellitus (NIDDM). It belongs to the meglitinide is an anti-Diabetic type-II class drug with of short-acting insulin secretagogues, which act by binding to the $\beta$ cells of the pancreas, and it stimulates and releases the insulin secretion levels [2]. Repaglinide incites an insulin response to early meals reducing the postprandial blood glucose levels. May be 1 month of a course is needed for a decrease in fasting blood glucose levels is seen. Meglitinides may have a common effect on slight growth in weight. The total average weight gain caused by meglitinides appears to be lower than that is caused by sulfonylureas. Due to their own mechanism of action, meglitinides it may because hypoglycemia [3]. The risk is thought to be lower than that of sulfonyl urea's since their action is presence on glucose-dependent. In addition to reducing postprandial and fasting blood sugar, meglitinides are shown to decrease glycosylated hemoglobin (HbA1c) levels, which are reflective of the last 8-10 weeks of glucose control. Repaglinide is thoroughly metabolized in the liver and excreted in bile salts. Approximately $90 \%$ of a single orally administered dose is eliminated in the face and $8 \%$ in urine. The chemical formula of $\mathrm{C}_{27} \mathrm{H}_{36} \mathrm{~N}_{2} \mathrm{O}_{4}$ and it is soluble in methanol and methylene chloride. But practically insoluble in watersolubility of approximately $20 \mu \mathrm{g} / \mathrm{ml}$ [4]. This review explores the reported analytical method, so far in the literature for the estimations of repaglinide in bulk drug, pharmaceutical formulation, and biological matrix. Various analytical methods such as spectrometric, highpressure liquid chromatography (HPLC), high-performance thin-layer chromatography (HPTLC), liquid chromatography-mass spectrometry
(LC-MS), and ultra-performance liquid chromatography (UPLC), capillary electrophoresis (CE), GC-MS, LC-ESI/MS, and diagnosis study has been used for analysis of Repaglinide [5].

\section{SAMPLE PREPARATION}

\section{Solubility}

According, to the Bio-pharmaceutical organization, the Repaglinide falls in BCS Class-II, which means high solubility and high perm ableness [6]. The $\mathrm{pH}$ scale of a saturated water resolution of repaglinide is bigger than seven the $\mathrm{P}^{\mathrm{ka}}$ is 4.1-5.7 and partition coefficient is 3.8. The solubility of the drug was tested in solvents ordinarily used for analytical methodology [7].

\section{Sample preparation strategies}

About $90 \%$ of the whole analysis of your time relies on sample resolution preparation during a most of the strategies. The standard of sample resolution preparation may be a key issue for the success of study. In most of the chemical analysis methodology is employed to distil water, and in generally fuel is employed an agent sample. The sample resolution preparation methodology for the summary extraction of repaglinide from biological matrices (plasma, serum and urine) embody super molecule precipitation with acetonitrile (ACN) and fuel, solid section extraction (SPE) mistreatment methanolphosphate buffer (PB), and methanol-water [8].

\section{ANALYTICAL METHODS}

\section{Spectrometry}

In literature regarding some ways area unit mentioned, for the determination of repaglinide victimization chemical analysis, of that ten ways area unit for the estimation of repaglinide alone, whereas different the opposite is for quantifying the repaglinide together with other medicine substance. The epitome of reported chemical analysis ways indicating the fundamental the fundamental $\left(\lambda_{\max }\right)$ solvent and limit of detection (LOD) is shown in Table 1. 
HPLC

\section{Biological samples}

Method development and valid of liquid natural process technique for concurrent estimation of repaglinide, metformin, pioglitazone, sitagliptin, glibenclamide, and gliclazide - Applications for Counterfeit Drug Analysis, the actual RP-HPLC technique was developed, and wide used oral antidiabetic area unit antidiabetic drug coordination compound (MTF), with few ordinarily prescribed by oral anti-diabetics, namely, and repaglinide (RPG), gliclazide (GLZ), pioglitazone coordination compound (PGZ), sitagliptin phosphate (SIT), and glibenclamide (GLB). The activity technique is separation carryout using gradient elution mode, and this method was valid in keeping with ICH Guidelines [19]

Separation and quantification of eight kind-II antidiabetic medicine on a high- performance liquid chromatography: Its applications to human plasma assay. Technique development and an analytical supported isocratic RP-HPLC action technique were developed and valid for the quantification and separation of eight kind-II antidiabetic drugs: Repaglinide, Nate glinide, rosiglitazone, pioglitazone, glipizide, gliclazide, glibenclamide, and glimepiride for his or her applications are utilized in human plasma assay technique. Antidiabetic is utilized as IS. The analysis was performed on onyx C18 column $(100 \times 4.6 \mathrm{~mm} .5 \mu \mathrm{m})$ employing a mixture of components [20].

\section{Pharmaceutical samples}

Analytical methods for the determination of repaglinide in bulk drugs and pharmaceutical dosage forms using RP-HPLC are shown in Table 2.

\section{STABILITY INDICATING METHOD}

In the literature few stability indicating methods are reported. Table 3 shows the summary of the methods.

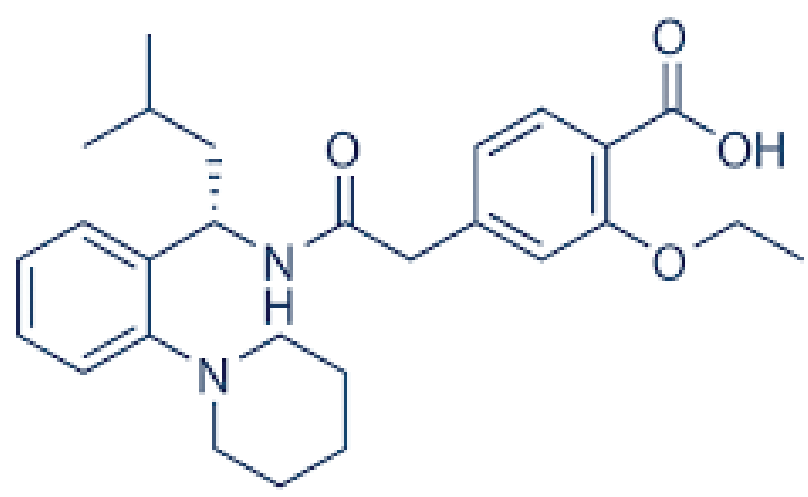

Fig. 1: Chemical structure of repaglinide

\section{LC-MS}

Validation of high-performance liquid chromatography-tandem mass spectrographic analysis (LC-MS /MS) technique was developed for the determination of repaglinide in human plasma. The analytical internal standard of, diazepam, is measure extracted from the plasma $(25 \mathrm{~m} / \mathrm{L})$ by liquid-liquid extraction with diethyl ether-dichloromethane $(60: 40, v / v)$. And separation on an XDB-C18 column, detection was administered into API 4000 mass spectroscopy with an ESI interface operative in numerous reactions watching mode [38].

Method for determination of LC-MS of anti-diabetic drug repaglinide in human plasma, the strategy was valid and developed over a linear range, and also the dried residue was reconstituted with $500 \mu \mathrm{L}$ of mobile part, and it absolutely was a cinematographic separation was achieved on a C18 analytical column, the strategy of the mode using MRM transitions $\mathrm{m} / \mathrm{Z} 453.3>162.2$ and $\mathrm{m} / \mathrm{Z} 389.0>201.1$ for the drug, and IS, severally. This technique was with success applicable for additional authentic human plasma samples from bio-equivalence studies [39].

Determination of liquid chromatography-tandem spectroscopic analysis of repaglinide and antidiabetic in human plasma and its application to pharmaceutical bioequivalence study, and therefore the technique was valid and developed for the simultaneous estimation of repaglinide and antidiabetic in human plasma employing a D6- antidiabetic and D5-Repaglinide an internal standard. When protein precipitation using acetonitrile because the precipitation solvent, each analytes and ISS were separated on a Venusil ASB C18 [150 mm× $4.6 \mathrm{~mm}, 5 \mu \mathrm{m}]$ through gradient elution using acetonitrile - $10 \mathrm{mmol}$ L-1 ammonium ion acetate because the mobile phase. The strategy is linear complete the $0.2-60.0 \mathrm{ng} / \mathrm{ml}$ concentration range of repaglinide and over the 4-1000 $\mathrm{ng} / \mathrm{ml}$ range of antidiabetic. A cinematographic complete run time of 7.5 min was achieved. The valid technique was fully applied to clinical information [40].

A bio-analytical methodology using 96-blade in thin-film microextraction (TFME) and LC-MS/MS methodology for estimation of Repaglinide (RPG) and a couple of its main metabolites' strategies were valid and developed for used of an in vitro metabolism study. The target analyses are extracted from the human microsomal medium by a 96-blade-TFME system using the low-price image "SPME multisampler" using C18 coating. Methodology development and validation showed by recoveries of around $90 \%$ for each analyzer's and also the methodology was applied to an in vitro metabolism study of Repaglinide using human liver microsomes and established to be required for these functions [41].

Degradation product is below the high temperature/humidity, UV/ Visible lightweight, in varied $\mathrm{pH}$ and oxidization are varied conditions

Table 1: Summary of a spectrometric method for the analysis of repaglinide either alone or in combination with other drugs such as gliclazide (GLZ) and metformin (MET)

\begin{tabular}{|c|c|c|c|c|c|}
\hline Compounds & Methods & Solvent/procedure & LOD $(\mu \mathrm{g} / \mathrm{ml})$ & $\lambda_{\max }(\mathrm{nm})$ & Ref. \\
\hline REPA, MET HCL & Second order method derivative & $\begin{array}{l}\text { Methanol: heptane sulfonates } \\
\text { sodium }[70: 30 \mathrm{v} / \mathrm{v}]\end{array}$ & $1.01,0.32-0.39$ & 234,252 & [9] \\
\hline REPA & $\begin{array}{l}\text { Zero order derivative method-A, first order } \\
\text { derivative method-B [absorbance maxima] }\end{array}$ & Methanol and water & $\begin{array}{l}0.00772 \\
-0.00864\end{array}$ & 245 & [10] \\
\hline REPA & Spectrophotometric method & methanol & 1.15 & 241 & [11] \\
\hline REPA & Shim-pack method & methanol & $0.5-0.1$ & 235 & {$[12]$} \\
\hline MET, REPA & $\begin{array}{l}\text { First-order derivative method [absorbance], } \\
\text { second order derivative [Q- absorbance ratio] }\end{array}$ & alcohol & $0.378,0.686$ & 240,292 & [13] \\
\hline REPA & Multiple - wavelength method & $\begin{array}{l}\text { Methanol, acidic, basic, buffers } \\
\text { solvent }\end{array}$ & $\begin{array}{l}0.97,0.26 \\
0.42,1.16\end{array}$ & $\begin{array}{l}438,281 \\
293,302 .\end{array}$ & [14] \\
\hline MET, REPA & UV Spectroscopic method & Methanol-water & $0.3-0.13$ & 210 & [15] \\
\hline REPA & Assay of UV spectrophotometric method & methanol & 0.278 & 237 & [16] \\
\hline REPA & Spectrofluorimetric method & methanol & 0.9986 & 379,282 & [17] \\
\hline Empagliflozin, MET & Spectrofluorimetric method & methanol & $0.20,0.19$ & 225,237 & [18] \\
\hline REPA, MET HCL & Second order derivative & methanol & $1.01,0.32,0.39$ & 234,252 & [9] \\
\hline
\end{tabular}


Table 2: Report of RP-HPLC method for determination of repaglinide either single or in a combination with other drugs in pharmaceutical dosage forms

\begin{tabular}{|c|c|c|c|c|c|c|c|}
\hline Study aim & Column & Mobile phase & Detection & $\lambda_{\max }(\mathrm{nm})$ & $\begin{array}{l}\text { Flow rate } \\
\mathrm{ml} / \mathrm{min}\end{array}$ & $\mathrm{LOD} \mu \mathrm{g} / \mathrm{ml}$ & Ref. \\
\hline $\begin{array}{l}\text { Chromatographic } \\
\text { separation of REPA PK } \\
\text { study }\end{array}$ & $\begin{array}{l}\text { StarC18, } \\
\text { analytical column } \\
{[4.5 \mathrm{~mm} \times 150 \mathrm{~mm}, 5 \mu \mathrm{m}]}\end{array}$ & $\begin{array}{l}\text { ACN:ammonium formate, } \\
{[60: 40, v / v]}\end{array}$ & UV & 244 & 1 & 10 & {$[21]$} \\
\hline $\begin{array}{l}\text { An optimization of MET } \\
\text { separation condition of } \\
\text { REPA }\end{array}$ & $\begin{array}{l}\text { BDS, Hypersil C18 } \\
{[150 \mathrm{~mm} \times 4.6 \mathrm{~mm}, 5 \mu \mathrm{m}]}\end{array}$ & $\begin{array}{l}\text { ACN: phosphate buffer } \\
{[60: 40 \mathrm{v} / \mathrm{v}] \text { with } 1 \%} \\
\text { triethylamine. }\end{array}$ & UV & 254 & 0.8 & 135.6-18.15 & {$[22]$} \\
\hline $\begin{array}{l}\text { REPA In bulk drug dosage } \\
\text { form }\end{array}$ & $\begin{array}{l}\text { C18 }[100 \times 4.6 \mathrm{~mm} \times 5 \mu \mathrm{m}] \\
\text { ODS Kromasil }\end{array}$ & $\begin{array}{l}\text { Methanol:phosphate buffer } \\
{[60: 40 \mathrm{v} / \mathrm{v}]}\end{array}$ & UV & 242 & 1 & 0.5 & [23] \\
\hline $\begin{array}{l}\text { Simultaneous estimation } \\
\text { with MET }\end{array}$ & $\begin{array}{l}\text { HypersilC18 } \\
{[250 \times 4.6 \mathrm{~mm}, 5 \mu \mathrm{m}]}\end{array}$ & Methanol:buffer $[40: 60 \mathrm{v} / \mathrm{v}]$ & UV & 242 & 1.0 & $0.5-2.0$ & {$[24]$} \\
\hline $\begin{array}{l}\text { Simultaneous REPA with } \\
\text { MET HCl }\end{array}$ & C18 & $\begin{array}{l}\text { Methanol- } 0.2 \% \text { : heptane } \\
\text { sulfonates sodium } \\
{[70: 30 \mathrm{v} / \mathrm{v}]}\end{array}$ & UV & 234,252 & $\begin{array}{l}0.68-0.89, \\
\text { and } \\
1.18-1.70\end{array}$ & $0.14-0.28$ & [9] \\
\hline $\begin{array}{l}\text { Determinations of REPA } \\
\text { in the tablet dosage form }\end{array}$ & $\begin{array}{l}\text { Agilent TC-C18 and } \\
\text { C21[250×4.6 mm, } 5 \mu \mathrm{m}]\end{array}$ & Methanol:water $[80: 20 \mathrm{v} / \mathrm{v}]$ & UV & 241 & 1.0 & 0.73 & [11] \\
\hline Determination of REPA & RP-C18 & $\begin{array}{l}\text { Methanol:triethylamine } \\
\text { with orthophosphoric acid } \\
{[50: 50 \mathrm{v} / \mathrm{v}]}\end{array}$ & UV & 235 & 1 & $0.5-0.1$ & [12] \\
\hline $\begin{array}{l}\text { Simultaneous with MET, } \\
\text { REPA }\end{array}$ & $\begin{array}{l}\text { YMC PACK AM ODS } \\
{[250 \mathrm{~mm} \times 4.6 \mathrm{~mm}, 5 \mu \mathrm{m}]}\end{array}$ & $\begin{array}{l}\text { Methanol: potassium } \\
\text { dihydrogen buffer } \\
{[70: 30 \mathrm{v} / \mathrm{v}]}\end{array}$ & PDA & 210 & 1 & $0.3,0.13$ & [15] \\
\hline $\begin{array}{l}\text { Simultaneous with six } \\
\text { antidiabetic drugs }\end{array}$ & $\begin{array}{l}\text { Altima C18 } \\
{[150 \times 4.6 \mathrm{~mm} \times 5 \mu \mathrm{m}]}\end{array}$ & $\begin{array}{l}\text { Methanol: Phosphate buffer } \\
{[70: 30 \% \mathrm{v} / \mathrm{v}]}\end{array}$ & UV & 230 & 1.0 & - & [25] \\
\hline $\begin{array}{l}\text { Assay method (PK, PD), } \\
\text { studies }\end{array}$ & $\begin{array}{l}\mu \text {-bond Apack C18 } \\
\text { column }\end{array}$ & $\begin{array}{l}\text { ACN:methanol:potassium } \\
\text { dihydrogen phosphate } \\
{[51: 11: 38 \mathrm{v} / \mathrm{v}]}\end{array}$ & UV & 245 & 1.5 & 1 & [26] \\
\hline $\begin{array}{l}\text { Simultaneous with MET } \\
\text { \& REPA }\end{array}$ & $\begin{array}{l}\text { Hypersil ODS C18 } \\
{[250 \mathrm{~mm} \times 4.6 \mathrm{~mm}, 5 \mu \mathrm{m}]}\end{array}$ & $\begin{array}{l}\text { ACN:ammonium } \\
\text { acetate buffer }[0.05 \mathrm{M}] \\
{[60: 40 \% \mathrm{v} / \mathrm{v}]}\end{array}$ & PDA & 271 & $3.13,10.01$ & $0.5-3.0$ & [27] \\
\hline Estimation of REPA drugs & $\begin{array}{l}\text { Analytical } \\
\mathrm{C} 18[250 \mathrm{~mm} \times 4.6 \mathrm{~mm}, \\
5 \mu \mathrm{m}\end{array}$ & $\begin{array}{l}\text { ACN:trifluoro acetic acid in } \\
\text { a water }[55: 45 \% \mathrm{v} / \mathrm{v}]\end{array}$ & UV & 285 & 1 & 1.73 & [28] \\
\hline $\begin{array}{l}\text { In vitro permeation } \\
\text { analysis studies of REPA }\end{array}$ & $\begin{array}{l}\text { RP C18 } \\
{[250 \mathrm{~mm} \times 4.6 \mathrm{~mm}, 5 \mu \mathrm{m}]}\end{array}$ & $\begin{array}{l}\text { ACN:ammonium acetate } \\
{[70: 30 \% \mathrm{v} / \mathrm{v}]}\end{array}$ & UV & 240 & 1 & $0.1-1.2$ & {$[17]$} \\
\hline
\end{tabular}

Table 3: The summary of stability indicating HPLC methods for determination of repaglinide either alone or in combination with other drugs

\begin{tabular}{|c|c|c|c|c|}
\hline Study aim & Stress condition & Detection & Types of study & Ref. \\
\hline $\begin{array}{l}\text { REPA simultaneous with MET } \\
\text { HCL in bulk drugs }\end{array}$ & $\begin{array}{l}\text { Acid, alkali, oxidation, dry heat } \\
\text { degradation }\end{array}$ & UV-230 & $\begin{array}{l}\text { Separation in presence of [dry heat] degradation } \\
\text { product }\end{array}$ & [29] \\
\hline $\begin{array}{l}\text { REPA estimation with MET } \\
\text { HCL in tablet dosage form }\end{array}$ & Acid, alkali, oxidation. & UV-232 & Separation in presence of degradation product & [30] \\
\hline MET simultaneous with REPA & $\begin{array}{l}\text { Thermal, photolytic, hydrolytic, } \\
\text { and oxidative. }\end{array}$ & UV-PDA-210 & $\begin{array}{l}\text { Separation of MET and REPA force degradation } \\
\text { product. }\end{array}$ & [31] \\
\hline REPA in bulk drug dosage & $\begin{array}{l}\text { Acidic, alkaline, hydrolytic, and } \\
\text { photolytic oxidation. }\end{array}$ & UV-237 & Assay method of degradation absorbance & [16] \\
\hline REPA in tablets & Oxidation & UV-243 & Degradation pathway & [32] \\
\hline $\begin{array}{l}\text { REPA in pharmaceutical } \\
\text { dosage }\end{array}$ & Stable to neutral and photolytic & UV-278 & $\begin{array}{l}\text { Separation in presence of REPA in force } \\
\text { degradation }\end{array}$ & [33] \\
\hline Determination of REPA & Acids, alkali, hydrolysis, oxidation & UV-240 & $\begin{array}{l}\text { Separation in presence of REPA in degradation } \\
\text { product }\end{array}$ & [34] \\
\hline $\begin{array}{l}\text { REPA in bulk and dosage } \\
\text { forms }\end{array}$ & $\begin{array}{l}\text { Hydrolysis, oxidation, photolysis, } \\
\text { and thermal }\end{array}$ & UV-216, 243 & $\begin{array}{l}\text { Separation in presence of REPA in degradation } \\
\text { product }\end{array}$ & [35] \\
\hline REPA in bulk drugs & Photolytic degradation & UV-237 & $\begin{array}{l}\text { Separation in presence of REPA degradation } \\
\text { product }\end{array}$ & [36] \\
\hline $\begin{array}{l}\text { Determination of REPA, PGL, } \\
\text { and RGL. }\end{array}$ & Acids, alkaline, oxidative & UV-225, 220, 240 & $\begin{array}{l}\text { Separation in presence of degradations and their } \\
\text { preparation with good extraction recoveries }\end{array}$ & [37] \\
\hline
\end{tabular}

of repaglinide and metformin. And second, a primary valid technique was LC-UV is examined, whether or not it is valid and determined those drugs within the presence of their own pharmaceutical degradation product and whether or not it's similar for estimating the degradation kinetic process [42].

\section{HPTLC}

Assay of antidiabetic medication in bulk and optimized methodology of nanoemulsion by stability-indicating valid methodology of highperformance thin-layer chromatography techniques, a simple selective, 
accurate, precise, and stability-indicating methodology of HPTLC, is analyzed by a repaglinide and each as pharmaceutical bulk product and in nanoemulsion pharmaceutical formulation methodology was valid. The technique was used in TLC metallic element pre-coated plates with colloid powder [G-60] F-254, as a stationary phase. The sample solvent system consists of chloroform/methanol/ammonia/ glacial ethanoic acid (7.5:1.5:0.9:0.1, v/v). Furthermore, the degraded product is nicely separated from the pure drug. Densitometric analysis of repaglinide ultraviolet illumination absorbance mode at $240 \mathrm{~nm}$ was distributed, the regression knowledge for the activity plots are going to be excellently showed [43]

An isocratic technique is precise, and rapid, selective, and economically, and reverse-phase HPTLC technique was established for the simultaneous estimation of product of metformin hydrochloride and repaglinide. HPTLC technique was developed and valid by employing a pre-coated silica gel G-60 F254 plates as stationary phase, using a methanol: ammonia sulfate $(0.25 \%)(\mathrm{pH}-5.7)(2.5: 7.5, \mathrm{v} / \mathrm{v})$ as mobile phase. The SP plates were scanned at roughly $243-236 \mathrm{~nm}$ for HP-LC and HP-TLC both are respectively [44].

The determination of HPTLC technique was developed by a quantitative estimation of repaglinide during a single pharmaceutical formulation $(2 \mathrm{mg}$ ). The action technique of repaglinide on silica Gel-60 powder F-254 TLC plate is SP and employing a chloroform:methanol:ammonia (4.5:0.8:0.05 v/v) as a mobile phase. Repaglinide showed a Rf worth $0.55 \pm 0.03$ and scanned UV at $288 \mathrm{~nm}$ using Camag TLC Scanner three. The method development was to be success, used for determining the assay of repaglinide tablet formulations [45].

Repaglinide is a widely used meglitinide class drug to treat diabetes mellitus. The degradation product as per ICH guidelines (hydrolysis, photolysis, dry heat, and oxidation) and a sensitive optimized assayed, stability-indicating method as developed for repaglinide in bulk and pharmaceutical dosage forms. The peak purity and quality of the drug were observed. Using HPTLC method, aluminum plates precoated with Silica Gel 60 F254 is a stationary phase and mobile phase solution used to consisted of methanol:toluene (2:8) and quantitation was done at the wavelength found to be at $242 \mathrm{~nm}$. The method was developed to be simple, specific, precise, and stability-indicating study [46].

High-performance thin-layer chromatography method has been A simple, accurate, precise, and rapid development and validated for the estimation of repaglinide in tablet dosage forms. The method development in TLC aluminum plates precoated with silica gel-G60-F 254 as a stationary phase. The mobile phase is used as a mixture of chloroform:methanol (9:1) v/v. The detection of the spot was carried out UV at $254 \mathrm{~nm}$. The analytical calibration curves were found to be linear between 300 and $3000 \mathrm{ng} \mathrm{mL}-1 \mathrm{Rf}$ value is $0.41 \pm 0.018$ with a regression coefficient of 0.9991 . The proposed methods can be successfully used to determine the drug content of marketed pharmaceutical product formulation. The determined by recovery studies was founds to be $97.98-98.89 \%$. The proposed method was validated according to various ICH guidelines [47].

\section{UPLC}

Method development and validation of simple stability indicating by UPLC method for the determination of repaglinide in pharmaceuticals dosages, A simple, precise, and accurate stability-indicating isocratic reverse-phase ultra-performance liquid chromatography method are determined. The method was developed using Water Equity BEH C18 (100 ó 2.1) mm, $1.7 \mu \mathrm{m}$ column with a mobile phase consisting of a mixture of potassium dihydrogen phosphate buffer of $\mathrm{pH} 3.2$ and acetonitrile $(40: 60 \mathrm{v} / \mathrm{v})$. The total run time for the assay was only $4 \mathrm{~min}$. The elution compound was detected at $245 \mathrm{~nm}$ with a UV detector. The standardization curve of mean peak area versus concentration showed an excellent [48].

The detailed electrochemical method was study and novel voltmeter, and LC methods are presented for the determination of repaglinide
(RPG) in pharmaceuticals. The HP-LC and UPLC methods are developed using core-shell columns with mobile phase solution consisting of 50:50; ACN:water $0.05 \%$ TFA; at PH: $3.0(\mathrm{v} / \mathrm{v})$ with UV detection at $215 \mathrm{~nm}$. Finally, the proposed development method was successfully applied for the determination of repaglinide in pharmaceutical dosage forms [49].

A Novel method for liquid chromatography method was developed for the simultaneous determination of the widely used oral antidiabetic, metformin hydrochloride with anti-diabetics comprising the meglitinides class in bulk, laboratory-prepared mixtures, and pharmaceutical products. It was applied in the presence of metforminreported by impurity (1-cyanoguanidine). Chromatography separation was achieved with isocratic elution mode using a mobile phase solution of acetonitrile: $0.01 \mathrm{M}$ sodium dihydrogen phosphate (pH: 2.8) (67:33; v/v) flowing through a LiChrospher NH2 (amino) Agilent column $(250 \times 4.6 \mathrm{~mm}-5 \mu \mathrm{m})$ at a rate of $0.8 \mathrm{~mL} / \mathrm{min}$ at ambient temperature in a run time of $4 \mathrm{~min}$. The detections of UV were carried out at $220 \mathrm{~nm}$. As per ICH guidelines, the present method was found to be rapid and simple, selective, economic, and needs for quality assessments of pharmaceutical products [50].

\section{GC-MS}

The short-acting insulin secretagogue commonly used as repaglinide for the treatment of type two diabetes. In this paper, metabolomics is the first research of dynamic urine metabolic profiling, and biomarkers of type-II antidiabetic mice treated with repaglinide based on GCMS. Twenty diabetic KK-Ay mice are orderly assigned to four groups and fed with repaglinide for $6,9,12$, and 14 weeks, respectively. Five C57BL/6 J mice are used as a good healthy control group and feed with water as a contrast. The PCA scores plot are identified 41 metabolites techniques, the results are demonstrated that repaglinide not only regulates the carbohydrates, and polyalcohol but also the organic acid in the organism. This work has illustrated the potential of metabolic to disease diagnosis, pharmacology, and pharma codynamics research studies [51].

\section{CAPILLARY ELECTROPHORESIS}

An applicability method was studied by 2,6-didi-o-methyl b-cyclodextrin (DM-b-CD) as the Chiral selector in capillary electrophoresis for fast and efficient chiral separation of repaglinide enantiomers. The method was systematically studied of the parameters affecting separation was performed with detection of UV at $243 \mathrm{~nm}$. The proposed new method was very speed and systematically, determined by efficient of separating enantiomers, and its applicable for the analyzing repaglinide enantiomers in pharmaceutical quality control of pharmaceutical productions [52].

The method of separation of repaglinide, brompheniramine maleate, dioxo promethazine hydrochloride, liarozole, carvedilol, homatropine hydrobromide, homatropine methyl bromide, venlafaxine, sibutramine hydrochloride, zopiclone, chlorphenamine maleate, and promethazine hydrochloride, was investigated the influence of types of ionic liquids concentration of BGE PH, long-chain length of ionic liquid cations on the resolution are explained and finally, the proposed methods were applied for the chiral impurity determination of Eszopiclone in the pure product of pharmaceutical tablets [53].

The separation of CE method in the non-aqueous medium was developed and validated for the determination of repaglinide in pharmaceutical formulation. The capillary electrophoresis was performed using a $75 \mathrm{~m} \times 90 \mathrm{~cm}$ fused silica capillary (76 cm effective length) and the detection of UV at $240 \mathrm{~nm} .0 .01 \mathrm{~mol} / \mathrm{l}$ solution of ammonium acetate in the mixture solution of methanol-acetonitrile $(3: 7, \mathrm{v} / \mathrm{v}), 30 \mathrm{kV}$ voltage, $30^{\circ} \mathrm{C}$ temperature and hydrodynamic injection ( $10 \mathrm{~m}$ bar, six s) was chosen as CE parameters studies. The solutions were prepared in methanol. The capillary electrophoresis method is demonstrated [54]. 
A method of capillary electrophoresis system for enantiomeric impurity test of repaglinide, un-coated fused silica capillary $(50 \mathrm{~m} \times 50 \mathrm{~cm}$, with an effective length of $(41 \mathrm{~cm})$ was used. The running buffer solution was composed of $30 \mathrm{mmol} / \mathrm{L}$ sodium dihydrogen phosphate and $5 \mathrm{mg} / \mathrm{ml}$ carboxymethyl-cyclodextrin ( $\mathrm{PH} \mathrm{3.5}$ ), and it can be used for determination of enantiomeric impurities in type-II antidiabetic [repaglinide] tablets [55].

\section{TITRIMETRIC AND ELECTRICAL METHODS}

An isocratic method was normal phase chiral HPLC method that was developed and validated for the enantiomeric separation of repaglinide, (S)- (+)-2-ethoxy-4-N [1-(2-piperidinophenyl)-3methyl-1-butyl] Amino carbonyl methyl] benzoic acid, an antidiabetic in the bulk drug substance. The solution is played an important role, in enhancing chromatography efficiency and resolution between the enantiomers. The method was developed extensively validated and proved to be robust. The developed method was found to be enantiomer selectivity, accurate, precise, and suitable for the quantitative determination of (R)-enantiomer in the bulk drug pharmaceutical substance [56].

A simple and rapid, method for a sensitive HPLC method for employing dual-channel colorimetric detection for the determination of repaglinide in human plasma is presented. The method was assayed by involving the extraction of repaglinide by ethyl acetate and its isocratic reversed-phase liquid chromatography with dual-channel colorimetric detection. The mobile phase solution composition was $50 \mathrm{~mm}$ disodium hydrogen phosphate/acetonitrile (60:40, v/v), PH of the mobile phase 7.5 set up with phosphoric acid. A total analysis, the first cell working potential was found to be +380 $\mathrm{mV}$, second was to be $+750 \mathrm{mV}$ (vs. Pd/H 2). It was confirmed that the method is suitable for pharmacokinetic studies or therapeutic study monitoring [57].

Stability-indicating studies of drugs are recognized as an essential part of the drug development method process. This rational study is used to, to understand the intrinsic stability indicating of the drugs and for the development of selective stability-indicating assay method was according to the ICH guidelines. As the stability stress studies of repaglinide have not been reported in the survey of literature review, the forced degradation product of repaglinide is generally carried out as per ICH guidelines, results in the formation of six pharmaceutical degradation products which have been characterized using LC-MS/MS in single and or combination with accurate mass measurements [58].

A method highly, sensitive and selective 3D excitation-emission of an accurate fluorescence technique was proposed to rapidly quantify the combined antidiabetics drug of repaglinide and irbesartan, and its application to PK study in rat and human plasmas with the Aid of second-order calibration curve method defending on alternating trilinear decomposition (ATLD) method. The enhanced excitationemission of matrix fluorescence light of repaglinide and irbesartan can be accurately solved and can simultaneously attain the optimal concentration level in the presence of a potentially strong intrinsic fluorescence from complexes biological matrices, such as human plasma and Rat, using the ATLD method was used, the results can be shown in a developed method and to maintain a second-order advantage in simultaneous determinations of the weak fluorescent analyses of interest in various biological plasma matrices study [59].

The antidiabetes mellitus and osteoarthritis both are highly exceptional diseases, combinations of anti-diabetic agents like repaglinide, and nonsteroidal anti-inflammatory drugs, like celecoxib which is commonly used in the treatment of clinical practice. In this study, a simple and sensitive bioanalytical HPLC method combined with a fluorescence detector (HPLC-FL) was developed and completely validated for the simultaneous quantification of repaglinide and celecoxib. A simple proteins precipitation procedure and reversed
C18 column with an isocratic mobile phase solution (a mixture of ACN and PH 6.0 phosphate buffer).and stability-indicating for this method was determined and validated as per the current FDA guidelines. The bioanalytical method was applied to the study of pharmacokinetic interactions between repaglinide and Celecoxib in vivo study. Furthermore, an in vitro metabolism and protein binding study using human [plasma/urine]materials highlighted the possibility of metabolism-based interactions between Celecoxib and repaglinide in a study of clinical settings [60].

A rapid method of stability-indicating thin-layer chromatography method was developed by a quantitative analytical determination of repaglinide in pharmaceutical tablets dosages. Moreover, the method was performed on RP-8 TLC plates with acetonitrile-PH 6.0 phosphate buffer solution, $60+40 \%(\mathrm{v} / \mathrm{v})$, as a mobile phase. The analytical method presented was found to be simple, reliable, accurate, and convenient for routine pharmaceutical analytical acceptance criteria established for TLC methods analytical performance fulfilled in the official literature [61].

For the point-of-care testing of the illegal fortification of repaglinide (Rep) in natural dietary supplements, a competitive chemiluminescent immunoassay (CLIA) was established, using horseradish peroxidase (HRP)-luminol-H2O2 system for signal amplification. Polyclonal antibodies for repaglinide were produced various immunizations technique. The method provided a result consistent with those from HPLC, and the proposed method could be used for rapid screening of repaglinide in natural dietary supplements and detecting repaglinide in serum after administration [62].

A method for the separation of six selected anti-hyper glycemic (antidiabetic) drugs (Repaglinide, tolbutamide, gliclazide, glimepiride, glibenclamide, and glipizide) was developed with the use of micellar electrokinetic chromatography. Any Two non-ionic polys (ethylene glycol) are based on surfactants Triton X-114 (reduced) and Genapol $\mathrm{X}-080$ was studies are neutral pseudo stationary phases. Pseudo stationary phase is obtaining by negative charges of separated antidiabetic drugs and non-ionic surfactants were employed for selectivity was altered [63].

Electrochemical method of Repaglinide is described at a mercury electrode has been investigated using DC, DPP, and CV of Repaglinide Is exhibit. And well-defined as irreversible oxidation peaks over by the DPP was used to determine Repaglinide in pure form. The proposed method was exactly applied to the analysis of repaglinide in pure and pharmaceutical dosage forms with an average recovery of 98.8$103.2 \%$. The results obtained agree good with the contents stated on the labels [64].

The sum of unknown impurities profiles of Repaglinide bulk drug product are detected by a simple isocratic method is reversed-phase high-performance liquid chromatography method. The impurities are isolated from the natural crude drug of repaglinide using an RPHPLC method. Based on the spectroscopic data of IR, NMR, and MS the structures of these impurities I, II, and IV and bi-product (III) were characterized as 4-carboxymethyl-2-ethoxy-benzoic acid (I), 4-cyclohexyl amino carbamoyl methyl-2-ethoxy-benzoic acid (II), 1-cyclohexyl-3-[3-methyl-1-(2-piperidine-1-yl-phenyl)-butyl]-urea (IV), and 1,3-dicyclohexyl urea (III), respectively [65].

\section{DIAGNOSIS}

Diagnosis of antidiabetes can be by determining the method of blood glucose level. In fasting conditions, the blood glucose level could be $>6.7 \mathrm{mmol} / \mathrm{L}$ or random glucose levels will be more than $10 \mathrm{mmol} /$ considered as diabetes. If there occur any doubts in the diagnosis, glucose tolerance test must be conducted to measure the glucose level in blood. Before the test, the patient needs to be on fast at least 10-12 h. During the test, the patient is advised to take $75 \mathrm{mg}$ glucose orally the test will be repeated after $2 \mathrm{~h}$. Thus, from the results 
observed can be determined by the glucose tolerance of the patient. In this diagnosis and therapy process, glucose levels can be determined using various pharmaceutical analytical methods.

\section{UV SPECTROSCOPY}

A blood glucose level can be determined by blood with a comparison of the UV spectrum of normal serum and antidiabetic blood serum. The antidiabetes mellitus leads to be changed in the condition of metabolism of fats acids, carbohydrates, lipids, and proteins. Moreover, the blood sample solution is usually collected from normal peoples and diabetic people the serum is separated by centrifugation of the blood samples solutions. The separated serum will further be diluted with deionized water and absorbance of the spectrum will be analyses [66].

\section{LC-MS AND GC-MS}

An analysis method of a $20 \mathrm{~mL}$ of the antecubital venous blood sample was collected and processed at $80^{\circ} \mathrm{C}$ for $6 \mathrm{~h}$ to take a serum sample can stand overnight at $4^{\circ} \mathrm{C}$ to achieve metabolic profiling. These samples are diluted to get $30 \mathrm{~g} / \mathrm{ml}$. The samples were mixed with internal standard and centrifuged for $10 \mathrm{~min}$. The supernatant is used to metabolite profiling using GC-MS or LC-MS method. In the presence of amino acids such as a tryptophan leucine, isoleucine, and valine, free fatty acids such as a palmitic acid and stearic acid and glycophosphatidylinositol confirms the occurrence of the diabetic patient condition [67].

Recent times HbA1c, the glycated hemoglobin was considered, as an important marker for the diagnosis of antidiabetes. Usually, HbA1c analytical methods are generally used, but based on differences in charge or structure. The different analytical techniques are included ion-exchange chromatography, CE, affinity chromatography, ELISA, and immune assay. Other analytical techniques methods are included in immune turbidimetry and ion-exchange HPLC. Among these methods, HbA1c measured by an HPLC is significantly greater than compared to other immune turbidometry methods [68].

The assay method of a urine sample, fatty acid profiles were established and based on the ultra-performance liquid chromatography quadrupole time of flight mass spectrometer, in this way, 19 fatty acids are added, and two pairs of hard-resolved isomers are easily separated, applied in metabolomics research of diabetes mellitus. 13 min, Q-TOF mass spectrometer reduced the matrix interference of urine samples by the high resolution of exact molecular weights. 93 cases of urine samples are analyzed. This work is complementary to the clinical diagnosis of diabetes mellitus patients; additionally, non-invasive testing of urine samples made it more convenient for examination while decreasing the patient's pain and improving their patient living conditions [69].

\section{CONCLUSION}

This review geared toward specializing in numerous analytical strategies according for the assay of repaglinide. A broad vary of techniques is out there for the estimation of repaglinide and [typeII antidiabetics drugs] in biological samples, and pharmaceutical indefinite quantity type. The analysis of revealed information unconcealed that chemical analysis strategies are the straightforward and economical strategies for estimation of repaglinide in pharmaceutical formulation. For analysis of repaglinide, and typeII antidiabetic medicine, HPLC-UV provides correct results and low price compared to advance detection techniques. HPLC with personal organizer detection was extensively used for the event of stabilityindicating assay strategies for separation and quantification of repaglinide within the presence of degradation product. This survey conjointly highlights the combined techniques that incorporate the economical separation of metabolites of repaglinide victimization HPLC with sensitive MS detection has become an imperative tool for quantification of repaglinide in biological fluids and pharmacokinetic studies. In comparison with activity strategies and its application of capillary dielectrolysis and diagnosing being thought-about as an alternate technique for separation of repaglinide. This review includes the entire detail of analytical strategies obtainable on repaglinide which can be substantiative for any analysis on the drug.

\section{AUTHORS' CONTRIBUTIONS}

All authors have donated equally to prepare this review paper. The final editing of the manuscript was carried out by Badikela Ramakrishna. The final version of the paper was approved by all main authors.

\section{CONFLICTS OF INTEREST}

All the authors declared that they have no conflicts of interest.

\section{AUTHORS' FUNDING}

Nil/Self.

\section{REFERENCES}

1. The Merck Index. $12^{\text {th }}$ ed. Monograph No. 8304; 1996. p. 1399.

2. Niemi M, Neuvonen PJ, Kivisto KT. The cytochrome P4503A4 inhibitor clarithromycin increases the plasma concentrations and effects of repaglinide. Clin Pharmocol Ther 2001;70:58-65.

3. Dabrowski M, Wahl P, Holmes WE, Ashcroft FM. Effect of repaglinide on cloned beta cell, cardiac and smooth muscle types of ATP-sensitive potassium channel. Diabetology 2001;44:747-56.

4. Neil MJ, Heckerman PE, Koch CB, Roman KJ. The Merk Index. An Encyclopaedia of Chemical, Drugs and Biological. 14 $4^{\text {th }}$ ed. White House Station NJ, USA: Merk and co. Inc.; 2012.

5. Internet Source-Product Information, JANUMET, JANUMET, XR; 2009. Available from: https://www.secure.healthlinks.net.au/content/ $\mathrm{msd}$ /pi.cfm?product=mkpjanum. [Last accessed on 2016 Nov 24].

6. Marbury TM, Ruckle JL, Hatorp V, Andersen MP, Nielsen KK, Huang WC, Strange P. Pharmacokinetics of repaglinide in subjects with renal impairment. Clin Pharmacol Their 2000;67:7-15.

7. Sweetman SC, editor. Martindale the Complete Drug Reference. $36^{\text {th }}$ ed. London: Pharmaceutical Press; 2009. p. 457.

8. Altun Z. New Techniques for Sample Preparation in Analytical Chemistry. Micro Extraction in Packed Syringe. Karlstad: Karlstad University Studies, Kakulteten for Teknik OchNaturvetenskap; 2008.

9. Fouad MM, Rashed NS. Development and validation of chromatographic and spectroscopic method for estimation of repaglinide and metformin hydrochloride in combined dosage forms. J Glob Trends Pharm Sci 2014;5:1844-8.

10. Smitaben HB, Jyotika GT, Minaxi G, Mukesh TM. Analytical method development of repaglinide in bulk and single component formulations. Int J Res Ayurveda Pharm 2013;4:136-7.

11. Dhole SM, Khedekar PB, Amnerkar ND. Comparison of UV spectrophotometry and HPLC Method for the determination of repaglinide tablets. Pharm Methods 2012;3:68-72.

12. Gandhimanthi M, Ravi TK, Renu SK. Determination of repaglinide in pharmaceutical formulation by HPLC with UV detection. Anal Sci 2003;19:1675-7.

13. Patel JR, Suhagia BN, Patel BH. Simultaneous spectrophotometric estimation of metformin and repaglinide in a synthetic mixture. Indian J Pharm Sci 2007;69:844-6.

14. Rajput SJ, Chaudhary BG. Validated analytical methods of repaglinide in bulk and tablet formulation. Indian J Pharm Sci 2006;68:130-2.

15. Joshi SS, Nahire RR, Shastri NR, Nath KV, Satish J. Validated stability indicating RP-HPLC, UV method for simultaneous determination of metformin and repaglinide. Acta Chromatogr A 2012;24:419-32.

16. Kumar DA, Kumar PK, Ranjit AD, Murthy PN, Kumar PA. Method development, validation, and stability study of repaglinide in bulk and pharmaceutical dosage form by UV spectrometric method. Int J Biol Pharm Res 2011;2:7-10.

17. Kaushal N, Jain S, Tiwari AK. Development of spectrofluorimetric and HPLC Methods for in vitro analysis repaglinide. Indian J Pharm Sci 2010;2:240-4.

18. Ayoub BM. Development and validation of simple spectrophotometric and chemometric methods for simultaneous determination of empagliflozin and metformin, applied to recently approved pharmaceutical formulation. Spectrochemical Acta A Mol Spectrosc 2016;168:118-22.

19. Elkady EF, El-Zaher AA, Elwy HM, Saleh MA. Validated liquid 
chromatographic method for simultaneous determination of metformin, pioglitazone, sitagliptin, repaglinide, glibenclamide and gliclazide application for counterfeit drug analysis. J Anal Bioanal Tech 2015;13:2-8.

20. Lakshmi KS, Rajesh T. Separation and quantification of eight antidiabetic drugs on a high performance liquid chromatography: Its application to human plasma assay. Int J Sch Res Netw Pharm 2011;7:521353.

21. Ruzilawati AB, Wahab MA, Imran A, Ismail J, Gan SH. Method development and validation of repaglinide in human plasma by HPLC and its application in pharmacokinetic studies. J Pharm Biomed Anal 2007:43:1831-5.

22. Tatiparthi RR, Duraiswamy D, Bonnoth CK. Method development and validation of metformin and repaglinide in rabbit plasma by RP-HPLC, bio- analytical and ADME laboratory services or FABAD. J Pharm Sci 2010;35:69-75.

23. Pingale PL, Nandasana PV. Development, and validation of RPHPLC method for the estimation of repaglinide in bulk drug and pharmaceutical formulation. Int J Drug Dev Res 2012;3:247-52.

24. Raja MA, Santoshi R, Banjo D, Rao K, Kumar DS. RP-HPLC method development and validation for simultaneous estimation of metformin and repaglinide in bulk and tablet dosage form. Asian J Res Pharm Sci Biotechnol 2015:3:33-40.

25. Yao J, Shi YQ, Rongli Z, Jin SH. Development of a RP-HPLC method for screening potentially counterfeit anti diabetic drugs. J Chromatogr 2007;2:254-9.

26. Adib N, Chi MS, Dabirgiaghi A, Hajimehdipoor H, Rastegar H, AbkariAdergani B. A new HPLC method for determination of repaglinide in human plasma and its application in bio-equivalence studies. Biosci Biotechnol Res Asia 2010;7:281-5.

27. Kalyankar TM, Kakde RB. Reversed-phase liquid chromatography method for simultaneous determination of metformin and repaglinide in pharmaceutical preparations. Res J Pharm Dosage Forms Technol 2011;3:233-7.

28. Bramanian RN, Giri SP, Nerella R, Duraipandian C, Seetharaman S. Stability indicating RP-HPLC method for estimation of repaglinide in rabbit plasma. Int J Appl Pharm 2019;3:206-10.

29. Deepar P, Bhai JP, Madhabhai MP. Stability indicating HPLC method for simultaneous determination of repaglinide and metformin hydrochloride in pharmaceutical dosage form. Asian J Res Chem 2013;3:500-5

30. Sonia K, Nappinnari M, Manikandan K. Stability indicating RP-HPLC method for the estimation of metformin hydrochloride and repaglinide as API and estimation on tablet dosage form. Int J Pharm Qual Assur 2016;3:46-50

31. Joshi SS, Nahire RR, Shastri NR, Surendranath KV, Satish J. Validated stability indicating RP-HPLC UV method for simultaneous determination of metformin and repaglinide. Acta Chromatogr A 2012;24:419-32.

32. EI-Shaheny RN. Validation stability indicating spectrofluorimetric methods with enhanced sensitivity for determination of repaglinide in tablets. J Fluoresc 2012;6:1587-94.

33. Mukesh C, Sharma SS. Stability indicating RP-HPLC method for determination and validation of repaglinide in pharmaceutical dosage form. Int J ChemTech Res 2011;3:210-6.

34. Deshpande K, Ranaware P, Madgulkar AR, Damle MC. Development and validation of stability indicating HPTLC method for determination of repaglinide. Res J Pharm Technol 2013;6:158-61.

35. Xavier CM, Basavaiah K, Ramesh PJ. Development and validation of two stability indicating UV-Spectrophotometric methods for the determination of repaglinide in bulk and dosage forms. Int J ChemTech Res 2013;5:72-9.

36. Mishra J, Nayak K, Sahoo SK. Development validation and stability study of UV spectrophotometric method for determination of repaglinide in bulk and pharmaceutical dosage forms. J Innov Appl Pharm Sci 2016;1:10-6.

37. EL-Sattar FM, Abdel-Aziz OA, Maya OS. Stability indicating RPHPLC methods for determination of some oral hypoglycaemic used drugs. Drug Invent Today 2010;2:443-53.

38. Zhang J, Gao F, Guan X, Sun YT, Gu JK, Fawcett P, et al. Determination of repaglinide in human plasma by high performance liquid chromatography tandem mass spectrometry. Acta Pharm Sin B 2011;1:40-5

39. Fayyad MK, Ghanem EH. Liquid chromatography tandem mass spectrometry method for determination of anti-diabetic drug repaglinide in human plasma. Am J Anal Chem 2014;5:281-90.

40. Xiao-Rong L, Xiao-Jian D, Yi-Fan Z, Jue-Fang D, Xiao-Yan C,
Da-Fang Z. Liquid chromatography tandem mass spectrometry simultaneous determination of repaglinide and metformin in human plasma and its application to bioequivalence study. Acta Pharm Sin 2013:4:547-53.

41. Simoes RA, Bonito PS, Mirnaghi FS, Bojko B, Pawliszyn J. Bioanalytical method for in vitro metabolism study of repaglinide using 96 blades thin film solid phase microextraction and LC-MS/MS. Bioanalysis 2015;7:65-77.

42. Gumieniczek A, Berecka A, Mroczek RT, Wastanowski K. Determination of chrmical stability of two oral antidiabetics, metformin and repaglinide in the solid state and solution using LC-UV, LC-MS, and FT-IR methods. J Mol 2019;24:4430.

43. Akhtar J, Fareed S, Aqil M. Stability indicating assay of repaglinide in bulk and optimized nano emulsion by validated high performance thin layer chromatography techniques. J Pharm Bioallied Sci 2013;3:184-90.

44. Ahir KB, Patella EM, Shah A. Simultaneous estimation of metformin hydrochloride and repaglinide in pharmaceutical formulation by HPTLC densitometry method. J Chromatogr Sep Tech 2013;4:2-5.

45. Jiladia MA, Pandya SS. Estimation of repaglinide in bulk and tablet dosage forms by HPTLC method. Int J Pharm Pharm Sci 2009;1:141-4.

46. Pandekiran D, Pranjali R, Madgulkar AR, Damle MC. Development, and validation of stability indicating HPTLC method for determination of repaglinide. Res J Pharm Technol 2013;2:158-61

47. Singh D, Kumar P, Kumar P. Development and validation of HPTLC method for the estimation of repaglinide in bulk and tablet dosage form. Int J Curr Trends Pharm Res 2013;1:189-93.

48. Xavier CM, Basavaiah K, Development and validation of a simple stability indicating UPLC method for the determination of repaglinide in pharmaceuticals. Thai J Pharm Sci 2013;37:84-94.

49. Gumustas M, Coskun G, Ozkan SA. Selective and sensitive determination of repaglinide in pharmaceuticals by voltametric and LC methods. Acad Rom Rev Roum Chim 2015;60:477-90.

50. EI-Zaher AA, Elkady EF, Elwy HM, El Makarim Saleh MA. A new rapid and economic liquid chromatographic method for simultaneous determination of meglitinides with metformin, application in the presence of metformin and repaglinide impurities and related compounds. J Iran Chem Soc 2018;15:61-74.

51. Yi H, Yi L, He R, Lv Q, Ren X, Zhang Z. Dynamic metabolic profiling of urine from Type-2 diabetic KK-AY MICE treated with repaglinide by GC-MS. J Anal Lett 2012;13:1862-74

52. Li C, Jiang Y. Analysis of repaglinide enantiomers in pharmaceutical formulations by capillary electrophoresis using 2, 6- Di-O-methyl cyclodextrin as a chiral selector. J Chromatogr Sci 2012;8:739-43.

53. Zuo L, Meng H, Wu J, Jiang Z, Xu S, Guo X. Combined use of ionic liquid and $\beta$-CD for enantio separation of 12 pharmaceuticals using $C E$. J Sep Sci 2013;3:517-23.

54. Berecka A, Gumieniczek A, Komsta L, Ingot T. Elaboration, and validation of a mew capillary electrophoresis method in non-aqueous milieu for the analysis of hypoglycaemics drug repaglinide in pharmaceuticals. Ann UMCS Pharm 2011;24:9-15.

55. Yuan XW, Sun JY, Wang SZ, Guo XJ. Determination of R (-)-isomer in repaglinide tablets by capillary electrophoresis. Zhejiang Da Xue Xue Bao Yi Xue Ban 2014;43:145-9.

56. Patil K, Rane V, Shinde D. A validated chiral LC method for the enantiomeric separation of repaglinide on amylose based stationary phase. J Chromatogr 2007;66:583-7.

57. Jirovsky D, Bartosova Z, Skopalova J, Maier V. Electro-chemical characterization of repaglinide and its determination in human plasma using liquid chromatography with dual channel coulometric detection. J Chromatogr B Anal Technol Biomed Life Sci 2010;31:2243-8.

58. Chander CP, Raju B, Ramesh M, Shankar G. LC-ESI-MS study of repaglinide and its forced degradation products. Rapid Commun Mass Spectrom 2017;32:72.

59. Fu H, Li H, Shao M, Yang TM. simultaneous determination of repaglinide and irbesartan in biological plasma using micellar enhanced excitation emission matrix fluorescence coupled with ATLD method. Sci Chin Chem 2016;59:5569-0.

60. Han DG, Kwok J, Seo SW, Kim JM. Pharmacokinetic evaluation of metabolic drug interactions between repaglinide and celecoxib by a bio-analytical HPLC Method for their simultaneous determination with fluorescence detections. Pharmaceutics 2019;11:382.

61. Gumieniczek A, Berecka A, Hopkala H. Quantitative analysis of repaglinide in tablets by reversed-phase-thin-layer-chromatography with densitometric UV detection. J Plan Chromatogr Med 2005;18:155-9.

62. Zheng L, Wang J, Wang Y, Song Z. A sensitive chemiluminescent immune-assay for point of care testing of repaglinide in natural dietary supplements and serum. Anal Bioanal Chem 2015;407:1973-80. 
63. Maier V, Znaleziona J, Jirovsky D, Skopalova J, Petr J, Sevcik J. Determination of anti-hyperglycaemic drugs in nano molar concentration levels by micellar electro kinetic chromatography with non -ionic surfactant. J Chromatogr 2009;20:4492-8.

64. Mandil HH, Sakur AA, Alulu S. Polarographic behaviour and quantification of the anti-diabetic drug repaglinide in pure form and pharmaceutical formulations. Int J Pharm Pharm Sci 2013;5:502-8.

65. Reddy KV, Babu J, Mathad VT, Eswaraiah S. Impurity profile study of repaglinide. J Pharm Biomed Anal 2003;32:461-7.

66. Hussein RO, Hussein HH, Hamza ZM. Diagnosis of diabetes mellitus in serum of pregnant women by using UV spectroscopy technique. J Kufa Phys 2015;7:92-6.
67. Lu Y, Wang Y, Ong CN, Subramaniam T, Choi HW, Yuan JM, et al. Metabolic signatures and risk of Type 2 diabetes in a Chinese population: An untargeted metabolomics study using both LC-MS and GC-MS. Diabetology 2016;59:2349-59.

68. Sherwani SI, Khan HA, Ekhzaimy A, Masood A, Sakharkar MK Significance of hbA1c test in diagnosis and prognosis of diabetic patients. Biomark Insights 2016;11:95-104.

69. Xu W, Zhang L, Huang Y, Yang Q, Xiao H, Zhang D. Urinary fatty acid composition and biomarkers discovery for Type-2 diabetic patients based on ultra-performance liquid chromatography quadrupole/time of flight mass spectrometry and multivariate statically analysis. J Anal Lett 2012;45:2649-62. 